\title{
PERUBAHAN SOSIAL, IJTIHAD DAN DINAMIKA HUKUM ISLAM
}

\author{
Salamah Eka Susanti*
}

\begin{abstract}
:
The Qur'an contains only a small number of detailed laws, while the sunna is limited to the cases that occurred in its time, so to solve new problems, ijtihad is required. In such a connection for a Muslim, new problems arising from the progress of science and technology, should not be confronted with confrontational passages, but must be solved by ijtihadi.Karena reality often occurs, that the development of society and public opinion faster the pace of the road from on the development of the law itself. The dynamics of people's lives are characteristic of change. Through the power of intention, power, and creativity, humans create cultural objects as a result of their creations. Changes that occur in society when observed can occur in various There are slow changes (evolution) and there are rapid changes (revolution). The social changes that occur in a society, directly or indirectly, affect institutions in various fields, such as government, economics, education, religion and so on. The continuation of an impact on the social system changes. When the law is faced with social change, it occupies one of its functions, which can function as a means of social control, and the law can serve as a means of social change. the characteristics of the law above is due to the inconsistency of social dynamics and the dynamics of law in the life of society. Unequaled dynamics of society and law, usually will bring social lag. From here, then comes a question whether Islamic law as a norm of God's determination can experience changes in accordance with the needs of the community? Ijtihad is an important factor for the development and development of Islamic law.Ijtihad done to answer
\end{abstract}

\footnotetext{
* Dosen tetap Prodi PIAUD, Fak. Tarbiyah INZAH Genggong Kraksaan
} 
the problems that arise in society that is not yet known legal status. ijtihad has a wide scope, the issues are not regulated explicitly dala $m$ al-Qur'an and sunna can be done ijtihad. In order for humans to have breadth in determining its activities according to its ability, needs and environment. Therefore ijtihad in the field of Islamic law in anticipating the dynamics of society and social changes concerning the values, behavior patterns, and social system of a society is a concern in establishing Islamic law. Thus ijtihad is the third source in the development of Islamic law.

Keywords: Social Change, Ijtihad, Law, Islamic.

\section{A. Pendahuluan}

Sejak periode awal sejarah perkembangan Islam, perilaku kehidupan kaum muslimin dalam keseluruhan aspeknyatelah diatur oleh hukum Islam. ${ }^{1} \mathrm{Al}$-qur'an pada awalnya diwahyukan sebagai respon terhadap situasi masyarakat saat itu, ${ }^{2}$ yang kemudian tumbuh dan berkembang lebih luas lagi.Seiring dengan berkembang Islam menyebar ke berbagai penjuru kawasan, maka muncul pula persoalan - persoalan baru yang berbeda dengan persoalan yang dihadapi kaum muslimin di masa rasulullah. Sedangkan al-qur'an hanya memuat sebagian kecil hukum -hukum terinci, sementara sunnah terbatas pada kasus-kasus yang terjadi di masanya, maka untuk memecahkan persoalan-persoalan baru, diperlukan ijtihad. ${ }^{3}$ Semangat ijtihad senantiasa dihidupkan oleh para

1 Sedemikian rupa pentingnya kedudukan hukum Islam dalam perkembangan Islam, sehingga mendorong seorang sarjana barat, joseph Schacht sampai pada suatu kesimpulan: bahwa tidak mungkin memahami Islam tanpa memahami hukum Islam. Joseph Schacht, An Introduction To Islami Law, (Oxford: University Press, 1996), hal.1

2 Dalam studi al-Qur'an dikenal sebagai pembahasan Asbabun Nuzul, dalam studi hadits dikenal pula pembahasan Asbabul Wurud.

3 Dalam kristalisasi mazhab-mazhab, hak untuk berijtihad pada awal abad keempat hijriyahmencapai titik kritis, dimana para fuqaha' dari berbagai madzab sunni memandang bahwa seluruh permasalahan yang esensial telah dibahas, dan tidak seorangpun yang memenuhi klasifikasi yang disyaratkan dalam berijtihad. Lihat Joseph Schacht, An Introduction OfIslamic Law, hal. 70-71. Bandingkan dengan NJ. Couson, A History OfIslamic Law, (Edin Burgh: Univercity Press, 1964), hal. 81. Disini 
fuqaha' meskipun diantara mereka ada yang lebih memilih status quo.

Jalaluddin al-Suyuti (W 911 H/1505 M) memberikan kritikan tajam kepada mereka yang mempertahankan dan mengabadikan taqlid. ${ }^{4}$ Sementara Ibn Taimiyah (661-728 H/1263-1328 M) tidak membenarkan adanya pendapat bahwa pintu ijtihad itu dinyatakan telah tertutup. ${ }^{5}$ Sedangkan Iqbal seorang pembaru dari India menyatakan dengan tegas bahwa ijtihad juga dapat dilakukan oleh legislatif (parlemen), ${ }^{6}$ Sebagai institusi yang mengeluarkan produkproduk perundang-undangan.

Timbulnya penemuan-penemuan baru yang mengubah cara hidup dan menggeser sudut pandang serta membentuk pola alur berpikir, menimbulkan pula konsekuwensi dan membentuk norma dalam kehipan bermasyarakat. Dalam kaitan tersebut bagi seorang muslim, persoalan-persoalan baru yang muncul karena kemajuan IPTEK, tidak harus dihadapkan dengan ketentuan-ketentuan nas konfrontatif, tapi harus dicari pemecahannya secara ijtihadi.Ijtihad yang pernah dilakukan oleh Umar Ibn Khattab kiranya telah cukup memberikan semangat sebagai acuannya. ${ }^{7}$ Karena realita sering terjadi, bahwa perkembangan masyarakat dan pendapat umum lebih cepat laju jalannya dari pada perkembangan hukum itu sendiri.

ia mengemukakan tesisnya bahwa, penutupan pintu ijtihad kemungkinan merupakan akibat tekanan - tekanan eksternal dan bukan karena sebab-sebab internal.

4 Jalaluddin al-Suyuti, Al-Raddu 'Ala Man Akhlada Ila A-Ardi Wa Jahila 'An AlIjtihada Fi Kulli Asrin Fardun, (Bairut: Dar Al-fikri, 1983) hal. 117-119. Lihat juga Jalaluddin al-Suyuti, tafsir al-ijtihad, (makkah: dar al-fikri, ttp), hal. 22. Disisi lain ia menyatakan bahwa: "nas itu telah berakhir pada persoalan-persoalan baru senentiasa muncul berkesinambungan maka, untuk memecahkannya wajib dilakukan ijtihad”.

5 Ibn Taimiyah mengemukakan pendapat itu telah diperkuat dari tokoh empet madzab, yaitu: Imam Hanafi, Imam Malik, Imam Syafi'I, Imam Ibn Hambalyang berisi: 1). Mereka tidak memngklaim bahwa ijtihad mereka itu yang paling benar. 2). Memberikan toleransi besar terhadap pemikiran hukum pihak lain. 3). Melarang taqlid. 4). Mengakui keterbatasan masing-masing sebagai manusia biasa. Lihat al'Asimi 'Abdurrahman Ibn Muhammad Bin Qosim, Majma' Al-Fatawa Syaikh Al-Islam Ibn Taimiyah, Juz XX, (Bairut: ttp), hal. 211.

6 Muhammad Iqbal, the reconstruction of religion thought in Islam, (New Delhi: Lahoti Fine Art Press, 1981), hal. 174. Apa yang dikemukakan oleh Iqbal itu, bisa disebut juga dengan ijtihad jama'i, yaitu pelaksanaan ijtihad yang dilakukan oleh sekelompok ahli dalam memecahkan suatu persoalan.

7 Tentang ijtihad Umar Bin Khattab, lihat Muhammad Rawwas Qal'aji, Maus'Ah Fiqh Umar Bin Kahttab, (Kairo: Dar Al-fikri Al-'arobi, 1969), hal. 170-191. 


\section{B. Dinamika Perubahan Sosial Dan Pengaruhnya Dalam Berijtihad}

Dinamika kehipan bermasyarakat merupakan ciriadanya perubahan. Tidak ada suatu masyarakat yang berhenti pada titik tertentu sepanjang masa, sejarah peradaban manusia telah membuktikan adanya perubahan yang konstan dan bergerak maju dalam masyarakan.Melalui daya karsa, daya rasa, dan daya cipta, manusia menciptakan benda-benda budaya sebagi hasil kreasi mereka.Perubahan-perubahan yang terjadi dalam masyarakat jika diamati dapat terjadi dalam bermacam-macam bentuk.Ada perubahan yang terjadi secara lambat (evolusi) dan ada perubahan cepat (revolusi).Perubahan lambat terjadi dengan sendirinya sebagai akibat adaptasi masyarakat dengan kondisi lingkungannya.Hal demikian berbeda dengan perubahan cepat yang muncul karena telah direncanakan. ${ }^{8}$ Perubahan yang direncanakan (Planned Change) adalah perubahan yang telah disiapkan oleh pihak-pihak yang menghendaki perubahan (Agent Of Change). Upaya demikian bisa disebut Social Engineering (rekayasa sosial) atau Social Planning (perencanaan sosial). Sedang perubahan yang tidak direncanakan (Unplanned Change) merupakan perubahan yang terjadi tanpa dikehendaki, berlangsug di luar jangkauan pengawasan masyarakat, sehingga segala akibat yang muncul dari perubahan itu bukan dikehendaki oleh masyarakat. ${ }^{9}$

Perubahan-perubahan sosial yang terjadi dalam suatu masyarakat, secara langsung atau tidak langsung, berpengaruh pada lembagalembaga dalam berbagai bidang, seperti pemerintahan, ekonomi, pendidikan, agama dan sebagainya.Kelanjutannya memberi dampak pada perubahan system sosial.

Manakala hukum dihadapkan kepada perubahan sosial, ia menempati salah satu dari fungsinya. Pertama, bisa berfungsi sebagai sarana sosial control (social control).dalam hal ini, hukum dilihat sebagai sarana untuk mempertahankan stabilitas sosial. Hukum berfungsi demikian, karena tertinggal dari perubahan sosial.Kedua, hukum bisa berfungsi sebagai sarana untuk mengubah masyarakat (Social Engineering).Dalam

8 Lihat Soerjono Soekanto, Sosiologi Suatu Pengantar, (Jakarta: Grafindo Persada, 1997), hal. 345-349. Lihat juga Allan G. Johnson, Human Arragements, (San Diego: Harcourt Brace Jovanivich, 1958), hal. 676-679.

9 Ibid. 
sarana untuk mengubahstruktur sosial, yakni apabila perubahan sosial terlambat dari perubahan hukum, sehingga hukum dengan segala perangkatnya memainkan peran untuk membawa masyarakat ke dalam suatu tatanan baru. ${ }^{10}$

Munculnya kedua karakteristik hukum diatas adalah karena tidak sejalannya dinamika sosial dan dinamika hukum dalam kehidupan masyarakat.Adakalanya perkembangan hukum yang tertinggal dari perkembangan unsur-unsur lain dalam masyarakat. Atau pada suatu kesempatan yang lain, bisa juga dinamika masyarakat tertinggal dari dinamika hukum. Ketidak seimbangan dinamika masyarakat dan hukum, lazimnya akan memunculkan kepincangan sosial (social lag).

Hukum Islam sebagai salah satu system yang dianut oleh pemeluknya dalam kehidupan individu dan masyarakat tidak lepas pula dari statemen-statemen tersebut diatas. Dari sini, kemudian muncul suatu pertanyaan apakah hukum Islam ${ }^{11}$ sebagai suatu norma ketetapan Allah dapat mengalami perubahan perubahan sesuai dengan kebutuhan masyarakat?

Terhadap pertanyaan tersebut kiranya memerlukan klasifikasi atau penjelasan.Bahwa isi kandungan al-Qur'an mempunyai dua dimensi, yaitu dimensi vertical dan horizontal.Pada dimensi vertical, al-qur'an mengndung aturan-aturan khusus yang mengatur hubungan manusia dengan ilahi.Dan penerapan hukum yang terkandung didalamnya tidak dapat diinterpretasikan diluar konteks praktek Rasulullah.Karena pola ubudiyah pada tatanan teoritis telah ditetapkan Allah, dan pada tatanan prakteknya telah dicontohkan oleh Rasulullah.

Hukum yang menyangkut ibadah telah diatur oleh nas-nas yang

${ }^{10}$ Lihat Sucipto Raharjo, Hukum Dan Perubahan Sosial, (Bandung: Alumni, 1983), hal. 193-194. Lihat juga Soerjono Soekanto, Pokok-Pokok Sosiologi Hukum, (CV Rajawali, 1988), hal. 125.

${ }^{11}$ Hukum Islam adalah totalitas religius yang mengatur perilaku kehidupan kaum muslimin. Jika hal itu dipahami sebagai produk pemikiran fuqaha'(Jurist Muslim), maka lazimnya disebut al-fiqh. Namun bila dipahami sebagai peraturan-peraturan hukum yang diwahyukan Allah, maka disebut syari'ah. Karenanya apa yang secara sederhana dinyatakan dengan istilah "Hukum Islam" sebenarnya lebih tepat dinamai keseluruhan tata kehidupan dalam Islam. Atau seperti yang dikatakan oleh MacDonal: hukum Islam Adalah the science of all things human and divine. Db. MacDonal, Develovement Of Muslim Theology Jurisprudence And Constitutional Theory, (New York: Charles Seribner's Sons, 1903), Hal.66. 
qath'i, karena tidak menyentuh kepentingan lahiriyah manusia yang bersifat ghair ma'qul m'na (tidak dapat dijangkau oleh akal pikiran manusia). Oleh karena itu, harus diterima apa adanya sesuai dengan nas. Dengan demikian, manusia tidak dapat menentukan bentuk ibadah lain selain yang telah ditetnukan oleh nas, hadits berikut ini menegaskan:

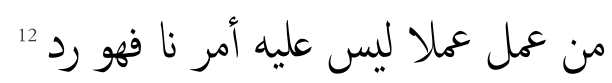

Barang siapa yang melakukan suatu amal (ibadah) yang tidak atas perintahku, maka tidak diterima.

Dengan demikian hukum dalam bidang ibadah bersifat ta'abbudi,dalam hal ini manusia tidak mempunyai wewenang untuk melakukan pembaruan. Karena segala bentuk ibadah yang baru dan menyimpang dari ketentuan nas dikriteriakan bid'ah.Sedang pada dimensi horizontal (hubungan antara manusia), penerapan yang terkandung didalam nas bersifat fleksibel.Kerena tidak dapat dipungkiri bahwa kemajuan peradaban dan budaya manusia senantiasa berkembang seiring dengan perkembangan ilmu dan teknologi (IPTEK).

\section{Ruang Lingkup Ijtihad}

Ijtihad merupakan faktor penting bagipembinaan dan perkembangan hukum Islam.Ijtihad dilakukan untuk menjawab permasalahan yang timbul di masyarakat yang belum diketahui status hukumnya.Sedemikian pentingnya peranan ijtihad dalam konspilasi hukum Islam, sehingga ada seorang ulama' yang menegaskan, bahwa tidak boleh suatu masa vakum dari mujtahid. ${ }^{13}$ Pendapat yang dikemukakan tersebut relevan dengan hadits Nabi:

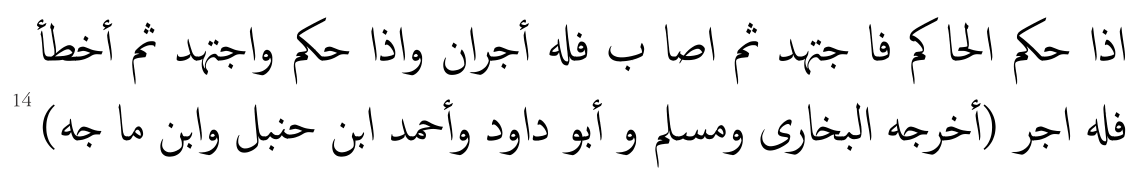

${ }^{12}$ Muslim, Shahih Muslim Bi Syarh Al-Nabawi, Juz Xii, (Bairut: Dar al-Fikr, 1981), hal. 16.

${ }^{13}$ Lihat Ibn Ali al-Subhi, Jam'u Al Jawami', Juz II, (Kairo: Dar al-Ihya' alKutub,ttp), hal 398. Lihat al-Suyuti, Al-Raddu, hal. 97.

${ }^{14}$ Hadits tentang ijtihad tersebut diriwayatkan oleh beberapa perowi, Muhammad Ajaj Bin al-Khatib, Al-Mujaz Fi Al-Hadits Al-Ahkam, (Damaskus: Al-Maktabah alJaddah, 1975), hal. 481. 
Apabila seorang hakim dalam memutuskan perkara dia berijtihad, kemudian ternyata ijtihadnya itu benar, maka dia mendapatkan dua pahala dan apa bila ijtihadnya itu keliru, maka ia mendapatka satu pahala.

Berkaitan dengan aktivitas ini, para ulama' sepakat mengenai lapangan atau ruang lingkup yang diperbolehkan melakukan ijtihad dan ruang lingkup yang tidak boleh melakukan ijtihad.al-Ghazali menegaskan bahwa ijtihad hanya boleh dilakukan terhadap hukun syara' yang tidak ada dalil qhat'inya.Yang dimaksud dengan hukum syara' disini menurut al-Ghazaliadalah pengecualian hukum akal dan ilmu kalam. ${ }^{15}$ Senada dengan pernyataan al-Ghazali tersebut, adalah penegasan yang dikemukakan oleh al-Muhtasib sebagai berikut:

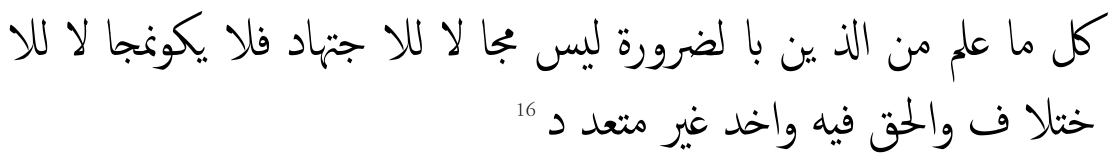

Semua yang diketahui secara pasti (qath'i) dalam agama, maka tidak ada tempat untuk melakukan ijtihad, dan tidak ada pula tempat untuk memperselisihkannya dan yang benar itu hanya satu tidk bervariasi.

Penegasan tersebut mempunyai arti bahwa, jika ada ijtihad pada masalah-masalah yang diketahui secara pasti (qath'i) berarti masih dapat pula dipeselisikan kebenarannya, sedangkan masalah yang qath'i itu tidak dapat diragukan lagi kebenarannya.

Pembahasan mengenai kriteria dalil qath'i dan dhanni ditemukan dikalangan ulama' ushul ketika mereka menganalisis kebenaran dari suatu sumber atau dalil.Pembahasan tersebut kemudian menimbulkan berbagai pendapat yang bervariasi.Mereka sepakat bahwa al-Qur'an dan hadits mutawattir adalah qath'i al-subut atau qath'i al-wurud, namun demikian, tidak semua dari nas yang qath'i al-wurud itu adalah qath'i aldilalah.

Abdul Wahab Khallaf berpendapat bahwa qathidilalah adalah: pertama, dalil yang maknanya jelas dan tidak mengandung takwil serta

${ }^{15}$ Al-Ghazali, Al-Mutasfa Min Ilmi Al-Syariah, (Bairut: Dar al-Kutub, 1971), hal. 482.

${ }^{16}$ Abd al-Majid al-Muhtasib, Ijtihad al-Tafsir fi Asri Al-Hadits, (Bairud: Dar alkutub al-fikri), hal. 482. 
tidak ada jalan lain memahami artinya kecuali itu, sebagai contoh ayat arti ayat ini jelas. Kedua, ayat-ayat mawaris yang mengandung pembagian harta pustakayang jelas bagi tiap-tiap ahli waris, sebagai contoh:

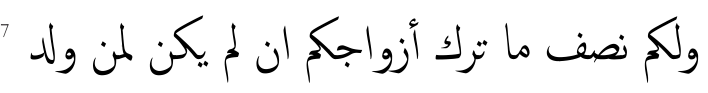

Dan bagimu (suami-suami) seperdua dari harta-harta yang ditinggalkan oleh isterimu jika mereka tidak mempunyai anak.

Ketiga, ayat al-Qur'an yang menjelaskan kadar hukuman had yang telah tercantum jelas mengenai kualitas dan kuantitasnya. ${ }^{18}$

Sementara itu dalam pembahsan dalil qath'i dan dhanni syathibi berpendapat, jika dalil itu berdiri sendiri, amat jarang ditemukan dalil yang mengandung makna yang asli.Kepastian makna suatu dalil hanya dapat ditangkap dan dimengerti ketika beberpa dalil dijajarkan menjadi satu sehingga pengertiannya saling melengkapi. Contohnya: kewajiban shalat tidak dapat dipahami hanya dari firman Allah dalam surat alBaqarah (2) ayat 43 yaitu:

(dan dirikanlah sholat), kata "اقيموا الصلاة itu sendiri mengandung dua makna, yaitu doa dan shalat. Kewajiban sholat itu baru bisa dipahami menurut Syathibi, setelah dalil-dalil tentang sholat diinduksi. Seperti dalil tata cara mengerjakan sholat dalam bepergian, al-Nisa' (4) ayat 101, begitu pula informasi bahwa shalat itu mencegah perbuatan yang keji dan mungkar, al-Angkabut (29) ayat 45, dan shalat adalah fardu yang ditentukan waktunya bagi orang-orang yang beriman, al-Nisa' (4) ayat 103, dan seterusnya. Dari himpunan ayat itu, dapat disimpulkan bahwa sholat itu wajib. ${ }^{19}$ Dalam kaitan ini Syathibi mengemukakan premis-premis yang harus dipenuhi agar satu dalil yang berdiri sendiri itu dapat dikategorikan qath'i. Premis-premis itu antara lain adalah (1) redaksi yang dimaksud bukan kata yang bersifat ganda (musytarak),(2) redaksinya bukan kata metaforis (majas), (3) tidak

\section{${ }^{17}$ QS. al-Nisa' (4) ayat 12.}

${ }^{18}$ Abd Al-Wahab Khalaf, 'Ilmu Ushul al-Fiqh, (Kairo: Dar al-Qalam, 1978), hal. 216.

${ }^{19}$ Al-Syathibi,al-Muwafaqat fi Usul al-Syariah, Juz I, (Bairut, ttp), hal.36-37. Dengan pensyarah Abdul Daraz. 
mengandung takhsis, (5) redaksinya tidak mengandung nasakh mansukh, (6) redaksinya tidak mengandung taqlid, (7) tidak bertentangan dengan akal yang logis ('adam al-mu'arid al-aqli). ${ }^{20}$

Yang menarik disini adalah katagorisasi tentang qath'i yang diberikan oleh Adib shalih menurutya, bahwa suatu lafadl itu bisa dikategorikan qath'i al-dilalah jika mencakup dua hal yaitu; (1) jika mangandung nilai aqidah agama (seperti iman kepada Tuhan, ke-Esaan-Nya, percaya malaikat-Nya, percaya kitab-Nya, percaya kepada hari kemudian).(2) Lafadl itu mengandung nilai-nilai universal dan tidak bertentangan dengan prinsip-prinsip moral yang utama (al-akhlaq al-karimah), seperti menegakkan keadilan, berbuat baik kepada kedua orang tua, menyambung silaturrahim dan menepati janji. ${ }^{21}$ Dengan demikian katagorisasi tentang qath'i yang dikemukakan oleh Adib Shalihini, dapat dipandang untuk melengkapi katagori-katagori yang diungkapkan sebelumnya.

Dalam pada itu ijtihad bisa diakui faliditasnya manakala seorang mujtahid itu memenuhi persyaratan-persyaratannya.Syatibi mengemukakan dua syarat bagi seorang mujtahid yaitu; pertama, seorang mujtahid itu harus benar-benar mengetahui maqasid al-syari'ah (tujuan hukum) dengan sempurna. Kedua, seorang mujtahid harus mampu melakukan istinbat hukum berdasarkan pemahaman dan pengertiannya terhadap tujuan syari'ah tersebut. ${ }^{22}$ Pada umumnya para ulama' usul mensyaratkan secara terinci terhadap seorang mujtahid yang melakukan ijtihad agar produk ijtihadnya dapat diakui. ${ }^{23}$

Berkaitan dengan ruang lingkup ijtihad, Ali Hasballah berpendapat, bahwa ijtihad mempunyai ruang lingkup yang luas, masalah-masalah yang tidak diatur secara tegas dalam al-Qur'an dan sunah dapat dilakukan ijtihad.Oleh sebab itu menurut Ali Hasballah, ijtihad adalah sumber ketiga dalam pengembangan hukum Islam. ${ }^{24}$ Ia juga menjelaskan keluasaan ruang lingkup ijtihad itu mencakup dhanni al-subut yang perlu

${ }^{20} \mathrm{Ibid}$.

${ }^{21}$ Muhammad AdibShalih, Tafsir al-Nusus fi al-Fiqh al-Islami, jiz I, (Bairut:alMaktab al-Islami, 1984), hal. 171.

22 Al-Syathibi, al-Muwafaqat, juz IV.hal. 104-105.

${ }^{23}$ Persyaratan-persyaratan seorang mujtahid lebih lengkap lagi lihat wahbah alZuhaili, Usul-al-Fiqh al-Islami, juz II, (Damaskus: Dar al-Fikri, 1986), hal. 1043-1051. 2424 Ali Hasballah, Usul al-Tasyri'al-Islami, (Kairo: Dar al-Ma'rifah, ttp),hal.79. 
diijtihadi sanatnya dan dhanni al-dilalah yang perlu dilakukan ijtihad mengenai penafsiran dantakwilnya. ${ }^{25}$ Dengan demikian, menurutnya ijtihad mempunyai ruang lingkup luas, yaitu seluas persoalan yang belum dijelaskan dalam nas dan belum disepakati ulama.

Kandungan al-Qur'an yang berkaitan dengan masalah-masalah muamalah diungkapkan dengan secara garis besar dan bersifat global (mujmal) dan sediki sekali yang terinci danqat'I, sehingga banyak peluang untuk melakukan ijtihad hukum yang sesuai dengan kemaslahatan manusia. Dengan demikian lapangan ijtihad adalah segala sesuatu yang tidak diatur secara tegas dalam nas untuk dilakukan reinterpertasi, secara terus menerus, dan juga masalah-masalah hukum yang sama sekali tidak diungkapkan landasannya dalam nas, agar manusia memiliki keluasan dalam menentukan aktivitasnya sesuai kemampuannya, kebutuhannya dan lingkungannya.

\section{Metode Pengembangan Hukum Islam}

Sebagaimana diketahui dalam kajianhukum Islam bahwa dalam pokok-pokok berijtihad adalah menggunakan al-Qur'an, al-Sunnah dan al-ra'yu.Al-ra'yu menurut Ibn Qayyim al-Jauziyyah adalah suatupandangan dan pemikiran yang timbul dari hati nurani setelah melalui perenungan dan penelitian yang mendalam.Ia timbul dari proses berpikir yang matang dan mendalam, dalam rangka mencapai suatu kebenaran berdasarkan indikasi yang ada. ${ }^{26}$ Kaitannya dengan upaya mengistinbatkan hukum, suatu pendapat dikatakan sebagai al-ra'yu yang shahih(benar), manakala pendapat itu diawalidengan penelitian dan renungan berpikir terhadap permasalahan yang akan ditetapkan hukumnya, kemudian dengan memperhatikan berbagai indikasi lingkungan yang melingkupi masalah tersebut, sehingga hasil suatu ijtihad seorang mujtahid itu tidak menyimpang dari kehendaksyara'. Urgensi penggunaan al-ra'yu bertambah besar, manakala menghadapi permasalahan yang tidak terangkum dalam nas. Sedangkan permasalahan yang tidak tercover dalam nasakan bertambah luas, sejalan dengan perkembangan iptek dan kemajuan

\section{$25{ }^{25} \mathrm{Ibid}$.}

${ }^{26}$ Ibn Qayyim al-Jauziyah, I'lam al-Muwaqqiin 'an Rabb al-Alamin, juz I, (Kairo: Dar al-Fikri, ttp), hal. 66. 
peradaban manusia itu sendiri. Sebagaimana kaidah berikutini: ${ }^{27}$ (bahwa sesungguhnya nasitu telah berakhir (final), sedangkan peristiwa atau problema hidup itu tidak pernah berakhir). Di sini al-ra'yu memegang peranan yang sangat potensial.Salah satunya penggunaan al-ra'yu itu adalah terumus dalam teori maslahah.Berdasarkan maslahahini pula, Umar Ibn Khathab pernah mendera peminum khamer delapan puluh kali. ${ }^{28}$ Sedangkan pada zaman Nabi peminum khamerhanya di dera empat puluh kali. Umar Ibn Khathab, seorang sahabat Nabi yang dianggap oleh jumhur ulama sebagai imam ahlira'yi,ia banyak berijtihad dan berfatwa dengan menggunakan pertimbangan maslahah. Setiap aktivitas yang mengandung manfaat, baik itu dari segi menarik atau menghasilkannya, maupun cara menolak atau menghindarkan dari bahaya dan kepedihan, pantas dinamai maslahah. ${ }^{29}$ Dan maslahahitu pada dasarnya adalah sesuatu yang membawa ke arah yang baik dan manfaat. Dalam pengembangan hukum Islam menggunakan metode maslahah mempunyai peran yang sangat essensial, terutama terhadap masalah yang timbul kemudian yang tidak ditunjukkeberadaannya dalam nas.

\section{E. Penutup}

Dinamika hukum Islam dan perubahan masyarakat adalah laksana dua sisi mata uang pada satu koin yang sama. Jika perubahan sosial tidak diikuti oleh dinamika hukum, akibatnya pada saat tertentu, hukum tidak lagi memenuhi kebutuhan masyarakat. Kondisi demikian mengakibat kan social lag (kesenjangan sosial) yaitu ketidakseimbangan dalam perkembangan lembaga-lembaga sosial yang mengakibatkan terjadinya kepincangan dan kesenjangan dalam masyarakat .Oleh karena itu ijtihad dalam bidang hukum Islam dalam mengantisipasi dinamika masyarakat dan perubahan sosial merupakan suatu hal yang mesti dilakukan dalam kajian hukum Islam, dinamika masyarakat dan perubahan sosial yang menyangkut nilai, polatingkah laku, dan system sosial suatu masyarakat sangat menjadi perhatian dalam menetapkan

${ }^{27}$ Abu Zahrah, Tarikh al-Madahib al-Islamiyah, (Kairo: Dar al-Fikri), hal. 16.

${ }^{28}$ Sulaiman Muhammad al-Farmawi, 'Umar IbnKhaththab waUsul al-Siasahwa alIdarah al-Hadisah, (Kairo: Dar al-Fikri al-Arabi, 1969), hal. 196.

29 Sa'id Ramadhaan al-Buthi, Dawabit al-Maslahah, (Bairut :Muassasah alRasalah, 1977), hal. 23. 
hukum Islam. Para ahli hukum Islam telah melakukan kodifikasi kaidah fiqhiyyah yang berkaitan dengan perubahan sosial dan dinamika masyarakat yang diinduksi dari nas. Kaidah-kaidah itu antara lain: (tidak dapat diingkari,perubahan hukum disebabkan oleh perubahan zaman). العادة محكير (adat kebiasaan yang berlaku dalam masyarakat dapat menjadi hukum). Bahkan Ibn Qoyyim al - Jauziyyah mengemukakan pernyataannya dalam berijtihad, yaitu: ${ }^{32}$

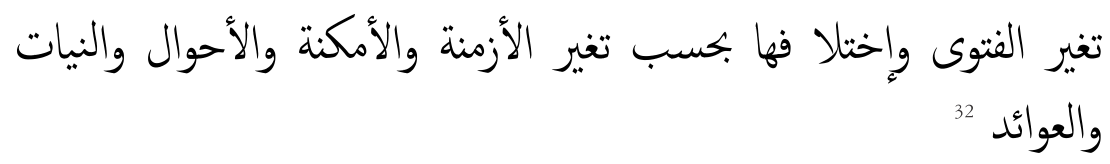

(berubahnya dan berbedanya fatwa itu sejalan dengan perubahan zaman,tempat,kondisi sosial,niat dan adat kebiasaan).

Kaidah-kaidah yang dikemukakan terdahulu itu memberikan gambaran dan mencitrakan bahwa hukum Islam itu dinamis tidak statis.

${ }^{30}$ Ahmad al-hajji, al-mukhdal al-fiqh al-qawaid al-kulliyah, (damaskus: dar alma'rifah, 1979), hal 60.

${ }^{31}$ Jalaluddin al-suyuti, al-Asybah wa al-Nadhair, (Bairut: Dar al-Fikri, 1996), hal. 119. Lihat juga Ali Ahmad al-Nadwi, al-Qawa'id al-Fiqhiyah, (Dar al-Qalam, 1987), hal. 313

${ }^{32}$ Ibn Qayyim al-Jauziyah, I'lam al-Muwaqqin 'an Rabb al-'Alamin, juz iii, hal. 1-2. 


\section{DAFTAR PUSTAKA}

Abu Zahrah,Ushul Al-Fiqh,Kairo,ttp.

Adib Shalih, Muhammad, Tafsir, Al-Nusus fi al-fiqh al-Islam, Bairut: Maktabah Dar Al-Fikri,1984.

Al-'Asyimi, Abd Al-Rahman, Majmak al-fatawa syaikh al-Islam Ibn Taimyyah, Bairut:ttp.

Al-Ghazali, al-Mustafa min 'Ilma al-syari'ah, Bairut: Dar al-Kutub, ttp.

Al-Hajji, Ahmad, al-Madkhal al-fighi al-Qawa'id al-Kuliyyah, Damaskus: Dar Ma'rifah, 1970.

Al-jauziyyah, Ibn al-Qayyim, 'Ilam al-Muwaqqi' in an Rabb al-'Alamin, Bairut:Dar al-Jail, 1973.

Al-Jauhili, Wahbah, Ushul al-Figh Al-Islami, Damaskus:Dar al-Fikri, 1986.

Al-Suyuthi, Jaluddin, al-Asybah wa al-Nadhair, Bairut:Dar Al-Fikri, 1996.

Al-Suyuthi, Jaluddin, al-Raddu 'Ala Man Akhlada Ila al-Ar<i wa Jahila 'an Ijtihada fi Kulli 'Asrin Fardun, Bairut:Dar AlFikri, 1983.

Al-syathibi, al-Muwafaqat fi Ushul al-Syari'ah, Bairut,ttp.

Al-Tamawi, Muhammad Sulaiman, Umar Ibn Khaththabb wa Ushul alSiasah wa al-Idarah, Kairo, 1969.

Ali Hasballah, Us-l al-Tasyri' al-Islami, Kairo:Dar al-Ma'rifah, ttp.

Coulson, NJ, A History of Islamic Law ,Edinburg:University Press, 1964.

Iqbal, Muhammad, The Reconstruction of Religious Thought in Islam, New Delhi, 1981.

Johnson, G Allan, Human Arrangements, San Diago,1985.

Khallaf, Abd al-Wahab, Ilmi Ushulal-Figh, Kairo:Dar al-Qalam, 1978.

McDonald Db, Development of Muslim Theology Jurispur-dence and Constitutional Theory, New York, 1903. 
Musa,Muhammad Tiwana,al-ijtihad wa mada Hajatuna' Ilahi, Mesir:Dar al-kutub, 1972.

Muslim, Shahih al-muslim bi syarh al Nawawi,Bairut:Dar al-Fikri,1981.

Raharjo, Sucipto, Hukum dan perubahan Sosial, Bandung:Alumni, 1983.

Rawwas, Muhammad, Maus-'ah Fiqh Umar Ibn Khaththab, Kairo:Maktabah jami' al Huquq,1981.

Soekanto, Soerjono, Pokok-pokok Sosialogi Hukum, Jakarta: Rajawali,1988.

Soekanto, Sorjono, Sosiologi suatu pengantar, Jakarta:Grafika Pesada, 1997. 